\title{
Correction to: Clinical, hematobiochemical, and pathological findings and therapeutic management of viperine snake envenomation in zebu cattle
}

\author{
A. U. Bhikane ${ }^{1}$ - R. K. Jadhav ${ }^{1}$ - P. S. Masare $^{2}$ - S. G. Chavhan ${ }^{3}$ \\ Published online: 8 March 2021 \\ (C) Springer Nature B.V. 2021
}

\section{Correction to: Tropical Animal Health and Production (2020) 52:3425-3437 https://doi.org/10.1007/s11250-020-02376-6}

Figure 8 caption of the originally published article was not correct and a duplicate of Fig. 7. Figure 8 is presented here with the correct caption.
Publisher's note Springer Nature remains neutral with regard to jurisdictional claims in published maps and institutional affiliations.

Fig. 8 Histopathological changes of viperine snake envenomation in Zebu Cattle. H\&E Stain. Liver: Marked coagulative necrosis \& vacuolative degeneration of hepatocytes. $(\mathbf{a} \& \mathbf{b}, \mathrm{Bar}=100 \mu \mathrm{m} \&$ Bar $=50 \mu \mathrm{m})$. Skin: Note the presence of marked intradermal and hypodermal hemorrhages. $(\mathbf{c} \& \mathbf{d}, \mathrm{Bar}=200 \mu \mathrm{m})$

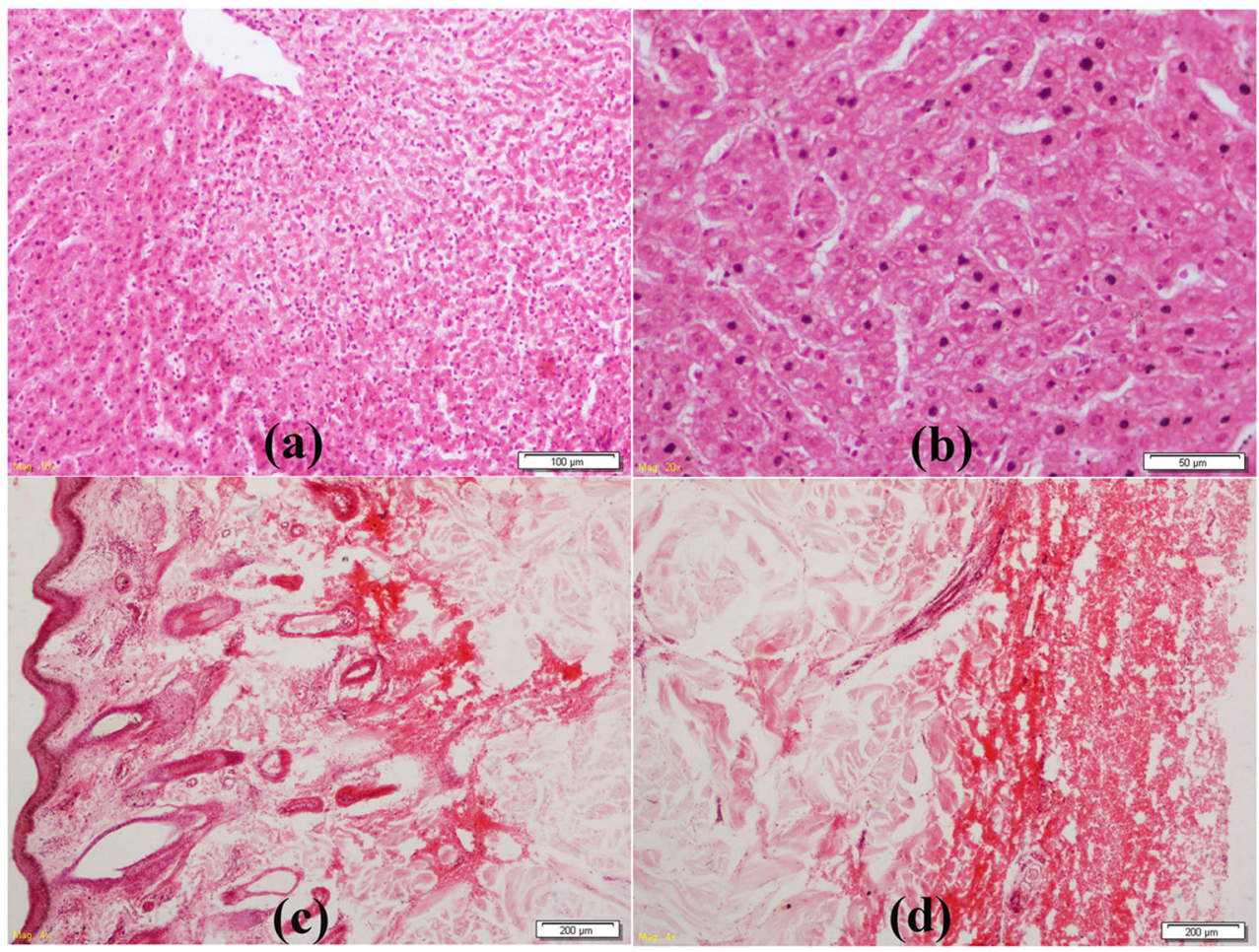

The online version of the original article can be found at https://doi.org/10. 1007/s11250-020-02376-6

R. K. Jadhav jadhavrk11@gmail.com

1 Department of Veterinary Clinical Medicine, Ethics and Jurisprudence, College of Veterinary and Animal Sciences, Udgir, Maharashtra, India
2 Department of Veterinary Clinical Medicine, Ethics and Jurisprudence, Mumbai Veterinary College, Mumbai, Maharashtra, India

3 Department of Veterinary Pathology, College of Veterinary and Animal Sciences, Udgir, Maharashtra, India 